\title{
NRC backs open access to test-ban data
}

[WASHINGTON] Scientific researchers should have open access to data collected for monitoring the Comprehensive Test Ban Treaty, says a panel of the US National Research Council (NRC), the operating arm of the National Academy of Sciences. The panel also calls for a substantial increase in funding for research to improve test-ban monitoring.

Although the treaty states that its provisions "shall not be interpreted as restricting the international exchange of data for scientific purposes", concerns were raised about open access to the monitoring data during the negotiation of the treatyin Geneva. According to members of the NRC panel, sensitivity is likely to centre on radionuclide data, which might be used by environmental groups to identify leaks from nuclear power plants.

Some countries are also thought to have expressed a more general concern that making the monitoring data widely available will allow outside bodies - even the news media - to draw premature conclusions about potential treaty violations, before the parties to the treaty have had a chance to analyse the data fully.

But Thorne Lay, of the Institute of Tectonics at the University of California, Santa Cruz, and chair of the NRC panel, dismisses the "irrational concern that $\mathrm{CNN}$ might scoop the national data center". Lay says that media organizations lack the necessary seismic data-processing capability but that, if they had it, "they could do this right now" using publicly available seismograms.
The test-ban treaty has been signed by 142 countries including the five nuclear weapons states (the United States, Russia, China, France and the United Kingdom). It calls for the setting-up of an International Monitoring System, consisting of seismic, hydroacoustic, infrasound and radionuclide sensors around the world, and reporting back to an International Data Centre in Vienna.

About 10 gigabytes of data per day will reach the centre, which will then distribute information to data centres in each of the countries participating in the treaty. It has been left to the treaty's preparatory commission, currently meeting in Vienna, to draft a policy on the distribution of data beyond the national data centres.

The US government has yet to formulate a policy on this question. Steven Bratt, principal programme director for nuclear treaty programmes in the office of the Secretary of Defense, says that the United States plans "to have a position on this by the time it comes up in Vienna", but the issue is "not at the top of the queue".

In the meantime, however, the Air Force Technical Applications Center at Patrick Air Force Base in Florida, which has been providing a prototype US national data centre for an international test of the seismic component of the treaty monitoring system, has told US seismologists that, for the time being, it will not provide open access to data from stations outside the United States. "We can't make a decision about other countries' data," says Bratt.

\section{First radiotelescope images from space}

[LONDON] The first images obtained using Very Long Baseline Interferometry (VLBI) with a Japanese radioastronomy satellite were released last week. The image of the quasar 1156+295 (right) is therefore one of the first images to have been produced using a radiotelescope in space.

Researchers at the National Radio Astronomy Observatory in Socorro, New Mexico, combined signals from the Japanese HALCA satellite and from ground-based stations in the National Science Foundation's Very Long Baseline Array (VLBA) and Very Large Array (VLA). The VLBA has 10 antennas and a maximum separation of 20 miles, and the VLA has 27 antennas and a maximum separation of 5,000 miles.

HALCA, launched in February by Japan's Institute of Space and Astronautical Science, is the first satellite designed for radioastronomy imaging. This image shows the quasar's core, bottom right, and a jet of subatomic particles emerging from the core towards the top left.

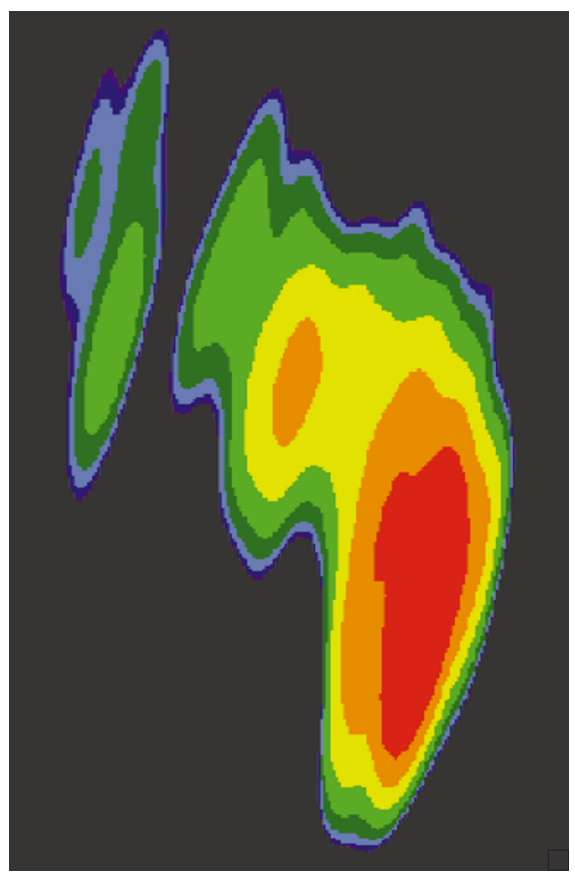

The NRC panel's report, which was published last week, argues that open, near-realtime access to the data is essential to support the United States' ability to monitor the treaty and to allow for use of the data in other fields of basic and applied research.

For example, the 60-station infrasound network should provide important information on volcanic eruptions in remote areas, as well as helping to detect meteors entering the Earth's atmosphere. And the seismic data, if available in near real-time, will help in the rapid location and size estimation of earthquakes - information that could help to accelerate emergency response efforts.

Despite statements from defence department officials supporting open data access, seismologists in the academic community have expressed scepticism about the intention of the US national data centre to distribute data freely. "This was a classified arena," says one NRC panel member. "They aren't used to people looking [over their shoulders]."

The potential for difficult relations between the defence and academic communities has also arisen in the context of the funding of basic research to support the test-ban treaty. The NRC report outlines the research necessary to support the United States' test-ban monitoring goals, and concludes that substantially increased funding will be needed. Its rationale is that "there are major unsolved problems in seismology, and that there will soon be a substantial flow of data from [the other monitoring] systems for which there is far less operational experience".

But funding has decreased, from about $\$ 12$ million per year in fiscal years 1995 and 1996 to $\$ 9.2$ million in the present fiscal year. At the same time, the defence department's share of the funding ( $\$ 8.8$ million), previously split into separate lines for basic, exploratory-development and advanceddevelopment research, has been consolidated into a single line controlled by the Nuclear Treaty Program Office (NTPO). This has prompted worries in the academic community that, as one panel member put it, "calibrating seismometers will suck up basic research money".

A more immediate concern is that the NTPO, through its administrative agent the Defense Special Weapons Agency, has apparently managed to spend only $\$ 3.8 \mathrm{mil}$ lion of the $\$ 8.8$ million allotted to it. One seismologist suggests that the agency "was not used to dealing with basic research and the academic community. They're used to dealing with transfers to national labs, not small (\$50,000-200,000) grants."

Steven Bratt of the NTPO admits: "We didn't do as well as we should have this year. Next year we're going to try to do better."

LauraGarwin 